\title{
Strong Association of Smoking with Lumbar Degenerative Spine Disease
}

\author{
Manoj Kumar Sharma* and Elena Petrukhina
}

Nerve Diseases, Medical Genetics and Neurosurgery, Tver State Medical Academy, Tver,170100, Russia

\begin{abstract}
Study Design: A prospective case control study.
Purpose of Research: To investigate the role of cigarette smoking in the development of early lumbar degenerative spine disease.

Summary of Background Data: Smoking is a growing and serious social as well as health problem all over the world. Cigarette smoking has many unfavourable impacts on human spinal column. The increased predisposition to low back pain in individuals who smoke has been well established. Exposure to nicotine has impact on disc metabolism and is believed to reduce the pain threshold of central nervous system.

Materials and Methods: The 300 patients included in the study were with a mean age of $40.6 \pm 6.0$ years who were diagnosed with lumbar degenerative spine disease confirmed by MRI. Among them 162 (54\%) patients were females. Patients were interviewed to assess their smoking status/history.

Results of Research: In the study it was found that $76.7 \%$ patients were smokers. The patient's who smoked; mean duration of smoking was $17.8 \pm 7.3$ years and mean for cigarettes per day was $16.3 \pm 7.4$ /day. Among the smokers $60 \%$ were between the ages of 30-40 years. The mean of pack year consumed by the patients was 15.2 \pm 10.2 .

Conclusion: From this study it is evident that cigarette smoking is a leading risk factor for lumbar degenerative spine disease and its association with early onset of lumbar degenerative spine disease. Further research is necessary to establish a temporal relationship between smoking and degenerative spine disease.
\end{abstract}

Keywords: Degenerative spine disease (DSD), smoking, nicotine.

\section{INTRODUCTION AND BACKGROUND}

Disc degeneration is influenced by various factors including age, mechanical, genetic, shear and toxins [1, 2]. Nutrition, metabolic disorders; low grade infection, autoimmune therapy and toxic factors such as nicotine to tobacco use have also been found to be responsible for degenerative changes to the spine [2]. Nicotine impacts disc metabolism by causing vasoconstriction and reduced blood supply to the vertebrae [3]. In vitro studies in cultured bovine cells have established that nicotine inhibits disc cell proliferation and synthesis of the extracellular matrix [4]. Animal studies in rats have shown passive smoking causes down regulation of collagen genes which is a precursor to disc degeneration [5]. It is believed exposure to nicotine reduces the pain threshold of the central nervous system [6]. Studies have suggested that the elevated CO-haemoglobin content in the blood of smokers causes an imbalance of oxidative metabolism and the resultant chronic cough may cause mechanical damage to the disc by increasing intradiscal pressure [7]. Smoking is implicated in speeding up aortic atherosclerosis and stenosis of arteries innervating the spinal column [8, 9].

*Address correspondence to this author at the Flat No: 21, House No: 111, Hostel No: 4, Street: St. Peterburg, Tver, 170036, Russia;

Tel/Cell: +7 90402619 31; E-mail: saurovjyoti@gmail.com
The objective of this study is to investigate the role of cigarette smoking in the development of lumbar degenerative spine disease.

\section{RESEARCH METHODOLOGY}

\section{Study Population}

The study investigated 300 patients between the ages of 30 and 50 years of age of Tver State Regional Hospital, Russia, who have clinical signs and symptoms of lumbar degenerative spine disease and were diagnosed with lumbar degenerative spine disease confirmed by MRI.

We recruited the patients in consecutive order from the outpatient department.

90\% of patients were diagnosed with L4-L5 and L5-S1 disc disease and $10 \%$ were with L3-L4 disc disease.

\section{Inclusion Criteria}

Patients diagnosed with lumbar degenerative spine disease for the first time. The patients had the signs and symptoms of degenerative spine disease for less than one year. 
All the patients had sciatic pain (back and leg pain). A few patients (25 patients) experienced numbness and altered sensation over the affected dermatome without any motor deficit.

\section{Exclusion Criteria}

Patients identified with: previously diagnosed degenerative disc or spine disease by MRI/CT scan or X-ray examination, previous surgery of lumbar spine, Congenital anomalies of lumbar spine, history of major trauma of lumbar spine, malignancy in the spinal region or any other malignancy, history of infection in the spinal region, serious internal disease such as, hypertension, diabetes mellitus, ischaemic disease of heart and lower limbs, bronchial asthma, BMI over 40, severe liver, renal and haematological disease. Patients with history of exposure to other risk factors like obesity, heavy physical activity (moving or pushing heavy furniture (75 lbs or more), carrying household items weighing 25 lbs or more up a flight or stairs, or shovelling coal into a stove. Standing, walking or walking down a flight of stairs while carrying objects weighing 50 lbs or more).

\section{Data Collection}

Patients diagnosed with lumbar degenerative spine disease, by MRI were interviewed to assess their smoking status/history. The grading of disc degeneration was done as per non modified Pfirrman's grading on T2-weighted Midsagittal fast spin-echo images. Distribution of patients as per Pfirrmans grading with grade $1-0$, grade $2-105$, grade 3 135 , grade $4-40$, grade $5-20$. To reduce the chances of observer and subjective bias we have taken the patients with duration of pain $<1$ year and patients were assessed by independent observers (a neurologist and a radiologist). The whole spine MRI screening was done and degeneration was predominantly confined to lumbar region. No gross changes of other region were noticed in MRI.

\section{Statistical Analyses}

All analyses were conducted using the statistical software package SPSS (version 10.0; SPSS, Inc., Chicago, IL, USA). Statistically significant differences were assumed when $\mathrm{p}<$ 0.05 . The regression modelling analysis was also conducted. Chi square test was performed to see the variant significance. Analysis of smoking history was done in cigarettes per day, duration of smoking in years and pack year consumption. The analysis was done in relation to age and gender distribution also.

\section{Ethical Issues}

The ethics committee of the academy approved all the studies and the patients gave their informed consent for participation.

\section{Results}

The 300 patients included in the study were between the ages of 30 and 50 years with a mean age of $40.6 \pm 6.0$ years, among which 138 patients (46\%) were males (mean age of $39.9 \pm 5.9$ years) and 162 patients (54\%) were females with mean age of $41.2 \pm 6.0$ years. Among these patients 230 (76.7\%) were smokers (Table $\mathbf{1}$ ).

As per Table $\mathbf{1}$ the mean (average) number of cigarettes smoke /day stands $16.3 \mathrm{cig} /$ day and average duration of smoking in years was 17.8 yrs. with mean pack year consumption of 15.2 pack years.

Among the smokers, highly significant 138 patients (48.7\%) were between the age of 30 - 40 years (Table 2).

In the study population out of 300 patients, only 70 (23.3\%) patients were non-smokers and among these 62 (88.6\%) patients were above the age of 40 years. Only 8 (5.5\%) patients were less than 40 years old (Table 2). We have taken the non-smoker group as control group. Our limitation was that we could not get a large control group because of non-availability of patients.

It is found that $20 \%$ smoked more than 20 cigarettes per day, of which $63.0 \%$ were between the age of $30-40$ years of age; $55.7 \%$ smoked $10-20$ cigarettes per day of which $54.6 \%$ were less than 40 years and $24.3 \%$ smoked less than 10 cigarettes per day, of which $69.6 \%$ were less than 40 years of age (Table 3 ).

The patients who smoked, 74 patients (32.2\%) were smokers for more than 20 years; 106 patients (46.08\%) were found to be smoking for $10-20$ years, while 50 patients (21.8\%) smoked for less than 10 years. In Table 4a the smoking related to age was illustrated and it shows patients aged between 30-40 years smoked an average of 15.6 cig/day for 14.1 years. The patients with age of 41-50years the average stand at $17.3 \mathrm{cig} /$ day for 23.3 years. It was a very significant amount of smoking as shown in Table $\mathbf{6 b}$. The $\mathrm{t}$ test and chi-square correlation (Table $\mathbf{4 b}$ ) was performed for these values it was found to be significant.

Out of 230 smokers, $53.9 \%$ were males, and $46.08 \%$ were females. For male smoking population mean value for cigarettes/day was $17.7 \mathrm{cig} /$ day and for duration of smoking 18.9 years and for female these were $14.7 \mathrm{cig} /$ day and 16.5

Table 1. Descriptive Statistics of smokers among the total patients

\begin{tabular}{|c|c|c|c|c|c|}
\hline & Number of Patients (Frequency) & Minimum & Maximum & Mean & Std. Deviation \\
\hline \hline Age & 300 & 30 & 50 & 40.6 & 6.0 \\
\hline cigar/ day & 230 & 4 & 35 & 16.3 & 7.4 \\
\hline Duration of smoking in years & 230 & 5 & 35 & 17.8 & 7.3 \\
\hline Consumption of cigarettes in pack years & 230 & 1.2 & 52.5 & 15.2 & 10.2 \\
\hline
\end{tabular}


Table 2. Cross Tabulation of Smoker and Non-smoker with Reference to Age Distribution

\begin{tabular}{|c|c|c|c|c|c|}
\hline & & & Smoker & Non-smoker & Total \\
\hline \multirow[t]{4}{*}{ Age } & \multirow[t]{2}{*}{$30-40$ yrs. } & Frequency & 138 & 8 & 146 \\
\hline & & $\%$ of group & $60.0 \%$ & $11.4 \%$ & $48.7 \%$ \\
\hline & \multirow[t]{2}{*}{$41-50 \mathrm{yrs}$} & Frequency & 92 & 62 & 154 \\
\hline & & $\%$ of group & $40.0 \%$ & $88.6 \%$ & $51.3 \%$ \\
\hline \multirow{2}{*}{\multicolumn{2}{|c|}{ Total }} & Frequency & 230 & 70 & 300 \\
\hline & & $\%$ Age & $76.7 \%$ & $23.3 \%$ & $100.0 \%$ \\
\hline
\end{tabular}

Table 3. Distribution of Cigarettes Consumed /Per Day by Smoking Population

\begin{tabular}{|c|c|c|c|c|}
\hline \multicolumn{2}{|c|}{} & Frequency & Percentage of Total no. of Patients & Percentage of Smoking Population \\
\hline \hline \multirow{3}{*}{ Smoker } & Upto 10 cig/day & 56 & 18.7 & 24.3 \\
\cline { 2 - 5 } & $11-20$ cig/day & 128 & 42.7 & 55.7 \\
\cline { 2 - 5 } & More than 20 cig/ day & 46 & 15.3 & 20.0 \\
\cline { 2 - 5 } & Total & 230 & 76.7 & 100.0 \\
\hline Non-smoker & Total & 70 & 23.3 & \\
\hline Total & & 300 & 100.0 & \\
\hline
\end{tabular}

years respectively. ' $T$ ' test was done for both frequency of cigarettes consumption per day and duration of smoking with gender distribution it was found a significant number of patients of both the genders smoke a significant amount of cigarettes per day for a long duration (Table 5).

Out of 230 smokers, 53.9\% were males, and 46.08\% were females. For male smoking population mean value for cigarettes/day was $17.7 \mathrm{cig} /$ day and for duration of smoking 18.95 years and for female these were 14.72 cig/day and 16.53 years respectively. ' $T$ ' test was done for both frequency of cigarettes consumption per day and duration of smoking with gender distribution it was found a significant number of patients of both the genders smoke a significant amount of cigarettes per day for a long duration (Table 5).

The consumption of cigarettes was considered in pack year and the mean stands at $15.2 \pm 10.2$ pack years (Table 1) and $66.1 \%$ of smokers smoked $1 / 2-1$ pack year (Table $6 \mathbf{6 a}$ ). This is very significant. In Table $\mathbf{6 b}$ chi square test was performed and value was significant.

\section{DISCUSSION}

Limited research has been conducted on the relationship between smoking and lumbar degenerative spine disease. Majority of the research focuses on the association between cigarette smoking and development of low back pain. Cigarette smoking has several significant unfavourable effects on the human spinal column. Heavy smokers are more susceptible to bony degradation resulting in degenerative disease of the spinal column as well increased incidence of vertebral injury. Nicotine has an adverse effect on osteoblastic cells. It not only reduces bone mineral density and blood supply to the bone, but also adversely affects cellular proliferation of osteoblasts, collagen synthesis and cellular metabolism of osteoblasts. Moreover, spinal fusion procedures are often less successful, clinically and radiographically in smokers compared to non-smokers [10]. Although smoking has been associated with low back pain and intervertebral disc degeneration, its significance as a causative factor remains to be elucidated [11, 12]. Russia leads the world in cigarette smoking.

It has been reported that there are 44 million adult smokers in Russia. The prevalence of smoking among males is reported to be $60 \%$, while the figure stands at $20 \%$ among females [13].

From the results it is evident that in the sample of patients studied, smoking is strongly associated with degenerative spine disease. It is also found that the early degeneration of disc and spine is quiet rare or uncommon in younger age group than that of smokers. In our study it was found $60 \%$ of smokers were of age between $30-40$ years. It is a serious concern. It was also evident from the result that most of the patients smoked a large number of cigarettes per

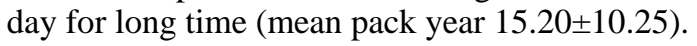


Table-4a. T-Test Group Statistics of Cigarettes Per Day and Duration of Smoking with Age Distribution

\begin{tabular}{|c|c|c|c|c|c|c|}
\hline & Age & Frequency & Mean & Std. Deviation & $\mathrm{t}$ & Sig. (2-tailed) \\
\hline cigar/ day & $41-50$ yrs & 92 & 17.3 & 7.1 & 1.6 & .093 \\
\hline \multirow{2}{*}{$\begin{array}{l}\text { duration of } \\
\text { smoking in years }\end{array}$} & $30-40$ yrs & 138 & 14.1 & 5.3 & \multirow{2}{*}{11.5} & \multirow{2}{*}{.000} \\
\hline & $41-50$ yrs & 92 & 23.3 & 6.6 & & \\
\hline
\end{tabular}

Table 4b. Correlations with Chi Square of Statistics of Cigarettes Per Day and Duration of Smoking with Age Distribution

\begin{tabular}{|l|l|c|c|}
\hline \multirow{4}{*}{ Cigar/day } & & cigar/ day & duration of smoking in years \\
& Pearson Correlation & 1 & $.186(* *)$ \\
\cline { 2 - 4 } & Sig. (2-tailed) &. & .005 \\
\cline { 2 - 4 } & Frequency (smoker) & 230 & 230 \\
\hline \multirow{2}{*}{ duration of smoking in years } & Pearson Correlation & $.186\left({ }^{* *}\right)$ & 1 \\
\cline { 2 - 4 } & Sig. (2-tailed) & .005 & 230 \\
\cline { 2 - 4 } & Frequency (smoker) & 230 & \multirow{2}{*}{2} \\
\hline
\end{tabular}

** Correlation is significant at the 0.01 level (2-tailed).

Table-5. T-Test Group Statistics of Cigarettes Per Day and Duration of Smoking with Gender Distribution

\begin{tabular}{|c|c|c|c|c|c|c|}
\hline & Gender & Frequency & Mean & S. D & $\mathrm{t}$ & Sig. (2-tailed) \\
\hline \multirow[t]{2}{*}{ Cigar/ day } & Male & 124 & 17.7 & 8.1 & \multirow{2}{*}{3.1} & \multirow{2}{*}{.002} \\
\hline & Female & 106 & 14.7 & 6.2 & & \\
\hline \multirow{2}{*}{$\begin{array}{l}\text { duration of smoking in } \\
\text { years }\end{array}$} & Male & 124 & 18.9 & 7.6 & \multirow{2}{*}{2.5} & \multirow{2}{*}{.002} \\
\hline & Female & 106 & 16.5 & 6.9 & & \\
\hline
\end{tabular}

Keeping in mind of quality of collecting and reporting of data, the patients were not selected from the previously diagnosed group. All the patients were recruited freshly. As the patients were not previously selected, the investigator had control over the quality of collection or reporting of the data.

Studies have demonstrated a significant association between smoking and low back pain after taking into account confounding factors $[14,15]$, as well as a dose -response relationship between present smoking status and incidence of back pain [16] and likelihood of prolonged back pain [17]. A recent meta-analysis [18] on the association between smoking and low back pain demonstrated that occurrence of low back pain differed with study population, year of publication, thereby indicating that aetiology of low back pain varied with region and ethnic populations.

Battie et al (1991) in a study of 20 pairs of identical twins established that disc degeneration was more common (18\%) among the individuals who smoked compared to their twins who did not. The study also revealed that the incidence disc degeneration was greater in the upper lumbar vertebrae compared to the lower lumbar spine [19]. Making use of magnetic resonance imaging of the lumbar spine, it was observed that disc degeneration was elevated in the smokers, although smoking history had no relationship with the incidence of pain. As the degenerative changes were observed across the lumbar spine it was hypothesized that smoking had a systemic effect. Similarly, histological evidence of disc degeneration in rabbits exposed to nicotine levels equivalent to those of heavy smokers also found [20].

It is important to keep in mind thee multifactorial aetiology of low back pain while interpreting the results as, it causal factors have been found to have a weak effect in multifactorial diseases [21]. A 14 year prospective study was carried out on middle-aged farmers and established that smokers were 10 times as likely to develop sciatica compared to their non-smoking counterparts [22]. Furthermore, people suffering from respiratory diseases have been found to exhibit an increased association between smoking and low back pain [7, 23] this is attributed to chronic cough and expiratory obstruction that results in mechanical stress on parts of the spinal column, similar to stress due to heavy physical work. 
Table 6a. Cross Tabulation of Cigarette Consumption in Pack Year with Cigarettes/Day

\begin{tabular}{|c|c|c|c|c|c|c|}
\hline & & & \multicolumn{3}{|c|}{ Cigarettes/ day } & \multirow[t]{2}{*}{ Total } \\
\hline & & & Up to 10 & $11-20$ & More than 20 & \\
\hline \multirow[t]{9}{*}{ Pack year } & \multirow[t]{3}{*}{$<1 / 2$} & Frequency & 24 & 6 & 0 & 30 \\
\hline & & \% within Pack year & $80.0 \%$ & $20.0 \%$ & $.0 \%$ & $100.0 \%$ \\
\hline & & $\%$ within cig/day & $42.9 \%$ & $4.7 \%$ & $.0 \%$ & $13.0 \%$ \\
\hline & \multirow[t]{3}{*}{$1 / 2-1$} & Frequency & 30 & 100 & 22 & 152 \\
\hline & & \% within Pack year & $19.7 \%$ & $65.8 \%$ & $14.5 \%$ & $100.0 \%$ \\
\hline & & $\%$ within cig/day & $53.6 \%$ & $78.1 \%$ & $47.8 \%$ & $66.1 \%$ \\
\hline & \multirow[t]{3}{*}{$>1$} & Frequency & 2 & 22 & 24 & 48 \\
\hline & & \% within Pack year & $4.2 \%$ & $45.8 \%$ & $50.0 \%$ & $100.0 \%$ \\
\hline & & \% within Cig/day & $3.6 \%$ & $17.2 \%$ & $52.2 \%$ & $20.9 \%$ \\
\hline \multirow{3}{*}{\multicolumn{2}{|c|}{ Total (smoker) }} & Frequency & 56 & 128 & 46 & 230 \\
\hline & & \% within Pack year & $24.3 \%$ & $55.7 \%$ & $20.0 \%$ & $100.0 \%$ \\
\hline & & $\%$ within Cig/day & $100.0 \%$ & $100.0 \%$ & $100.0 \%$ & $100.0 \%$ \\
\hline
\end{tabular}

Table 6b. Chi-Square Tests of Pack Year with Cigarettes /Day

\begin{tabular}{|c|c|c|c|}
\hline & Value & Df & Asymp. Sig. (2-sided) \\
\hline \hline Pearson Chi-Square & $87.9(\mathrm{a})$ & 4 & .000 \\
\hline Likelihood Ratio & 79.8 & 4 & .000 \\
\hline Linear-by-Linear Association & 64.4 & 1 & .000 \\
\hline No. of Cases (smoker) & 230 & & \\
\hline
\end{tabular}

(a)- 0 cells $(.0 \%)$ have expected count less than 5 . The minimum expected count is 6.00

Moreover, smoking is a known risk factor for osteoporosis [24, 25], which causes low back pain. Studies have demonstrated an increase in the level of circulating proinflammatory cytokines [26, 27], which results in an elevated sensitivity to pain [27]. Smoking may cause degenerative changes to spinal structures by alteration in genetic expression in the intervertebral discs; it down-regulates collagen genes and up-regulates aggrecan and the tissue inhibitor of metalloproteinase-1 genes [5].

The increased predisposition to low back pain among individuals who smoke has been well established [28]. Studies have found that smokers are nearly twice as likely (OR $1.3-2.5$ ) to develop low back pain than their nonsmoking counterparts [6, 7, 29-31]. The relationship between cigarette smoking and low back pain is found to be dose dependent [9]. It is believed that the presence of confounding factors such as genetic factors, lifestyle and occupational hazards also play a role in the development of degenerative spinal disease [28, 31, 32].

The elevated serum proteolytic activity accelerates degeneration of a previously degenerated neovascularised disc [33]. Moreover, the increased proteolytic activity may be responsible for weakening of spinal ligaments leading to spinal instability, thereby accounting for the increased likelihood of low back pain among cigarette smokers.

The undesirable effect of cigarette smoking has been demonstrated for outcome of spinal surgery. Cigarette smoking is a risk factor for both non-union and poor clinical outcome in lumbar spine fusion surgery. In posterolateral spine fusion procedures, smoking is associated with reduced fusion rates due to an unfavourable healing environment [34].

For the assessment of lumbar disc degeneration grading system developed by Pfirrman et al is extensively used. In this system of grading, Grade I: the structure of the disc is homogeneous, with bright hyperintense white signal intensity any normal disc height. Grade II: the structure of the disc is inhomogeneous, with the hyperintense white signal. The distinction between nucleus and annulus is clear, and the disc height is normal, with or without a horizontal gray bands. Grade III: the structure of the disc is inhomogeneous, with intermittent gray signal intensity. The distinction between nucleus and annulus is unclear, and the disc height is normal or slightly decreased. Grade IV: the structure of the 
disc is inhomogeneous, with hypointense dark grey signal intensity. The distinction between the nucleus and annulus is lost; the disc height is normal or moderately decreased. Grade V: the structure of the disc is inhomogeneous, with hypointense black signal intensity. The distinction between nucleus and annulus is lost, and the disc space is collapsed. Grading is performed on T2-weighted Mid-sagittal fast spinecho images [35].

The modified Pfirrmann grading comprises 8 grades of lumbar disc degeneration. The 8 grades represented progression from normal disc degeneration to severe disc degeneration. Grade 1 corresponds to no disc degeneration while grade 8 corresponds to end stage degeneration [36].

\section{CONCLUSION}

In order to demonstrate a causal relationship between smoking and degenerative spine disease it is essential to establish a progressive or temporal relationship, in which cigarette smoking precedes onset of spinal degeneration. This cannot be demonstrated effectively in a cross sectional study due to ethical restraints. Further research is necessary to establish a temporal relationship between smoking and degenerative spine disease. From this study it is evident that cigarette smoking is a leading risk factor for degenerative spine disease as well as early onset of degenerative spine disease. It is looking obvious that the smoking initiates the early degenerative process by stimulating the degenerative gene in our body, which is responsible for early onset of degenerative spine disease and other degenerative diseases. But there is no concrete evidence of it till now. This topic needs more elaborate discussion as smoking is a major health hazard all over the world

Due to the cross sectional study design, a strong causal relationship between smoking and degenerative spine disease could not be established. A strong association between smoking and degenerative spine disease was found. Another limitation of the study was the absence of large number of literatures. Third limitation was that small control group due to non-availability of large number of non-smoking patients.

\section{ABBRIVATIONS}

$$
\begin{array}{lll}
\text { S.D } & = & \text { Standard deviation. } \\
\text { Cig/day }= & \text { Cigarettes per day. } \\
\text { MRI- }= & \text { Magnetic resonance imaging. } \\
\text { CT- } & = & \text { Computer tomography. }
\end{array}
$$

\section{CONFLICT OF INTEREST}

The authors confirm that this article content has no conflicts of interest.

\section{ACKNOWLEDGEMENT}

1) Mrs Vida Dias Sharma: for compiling, editing and correcting the text.

2) Mr Sudhir Kale: for statistical analysis.

\section{REFERENCES}

[1] Videman T, Saarela J, Kaprio J, et al. Associations of 25 structural, degradative, and inflammatory candidate genes with lumbar disc desiccation, bulging, and height narrowing. Arthritis Rheum 2009; 60(2): 470-81.

[2] Hadjipavlou AG, Tzermiadianos MN, Bogduk N, Zindrick, MR. The pathophysiology of disc degeneration: a critical review. J Bone Joint Surg Br 2008; 90(10): 1261-70.

[3] Frymoyer JW, Pope MH, Clements JH, Wilder DG, MacPherson B, Ashikaga T. Risk factors in low-back pain. J Bone Joint Surg 1983; 65-A: 213-8.

[4] Akmal M, Kesani A, Anand B, Singh A, Wiseman M, Goodship A. Effect of nicotine on spinal disc cells: a cellular mechanism for disc degeneration. Spine 2004; 29 (5): 568-75.

[5] Uei H, Matsuzaki H, Oda H, Ge Nakajima S, Tokuhashi Y, Esumi $\mathrm{M}$. Gene expression changes in an early stage of intervertebral disc degeneration induced by passive cigarette smoking. Spine 2006; 31(5): 510-4

[6] Brage S, Bjerkedal T. Musculoskeletal pain and smoking in Norway. J Epidemiol Commun Health 1996; 50: 166-9.

[7] Frymoyer JW, Pope MH, Costanza MC, Rosen JC, Goggin JE, Wilder DG. Epidemiologic studies of low-back pain. Spine 1980; 5: 419-23.

[8] Auerbach O, Garfinkel L. Atherosclerosis and aneurysm of aorta in relation to smoking habits and age. Chest 1980; 78: 805-9.

[9] Sackett DL, Gibson RW, Bross IDJ, Pickern JW. Relation between aortic atherosclerosis and the use of cigarettes and alcohol. N Engl J Med 1968; 279: 1413-20.

[10] Hadley M, Reddy S. Smoking and the human vertebral column: a review of the impact of cigarette use on vertebral bone metabolism and spinal fusion. Neurosurgery 1997; 41(1): 116-24.

[11] Leboeuf-Yde C. Smoking and low back pain: a systemic literature review of 41 journal articles reporting 47 epidemiologic studies. Spine 1999; 24: 1463-70.

[12] Goldbert MS, Scott SC, Mayo NE. A review of the association between cigarette smoking and the development of nonspecific back pain and related outcomes. Spine 2000; 25: 995-1014.

[13] Holmes D. Smoking in Russia: will old habits die hard? Lancet 2011; 378(9795): 973-4.

[14] Tsai SP, Gilstrap EL, Cowles SR, Wadell LC, Ross CE. Personal and job characteristics of musculoskeletal injuries in an industrial population. J Occup Med 1992; 34: 606-12.

[15] Eriksen WB, Brage S, Bruusgaard D. Does smoking aggravate musculoskeletal pain? Scan J Rheumatol 1997; 26: 49-54.

[16] Deyo RA, Bass JE. Lifestyle and low-back pain. The influence of smoking and obesity. Spine 1989; 14: 501-6.

[17] Leboeuf -Yde C. Does smoking cause low back pain? Results from a population-based study. J Manipulative Physiol Ther 1996; 19: 99-108.

[18] Shiri R, Karppinen J, Leion-Arjas P, Solovieva S, Viikari-Juntura E. The Association between smoking and Low back pain. Am J Med 2010; 123: 87.e7-87.e35.

[19] Battie MC, Videman T, Gill K, et al. Smoking and lumbar intervertebral disc degeneration: an MRI study of identical twins. Spine 1991; 16(9): 1015-21.

[20] Iwahashi M, Matsuzaki H, Tokuhashi Y, Wakabayashi K, Uematsu Y. Mechanism of intervetebral disc degeneration caused by nicotine in rabbits to explicate intervertebral disc disorders caused by smoking. Spine 2002; 27: 1396-401.

[21] Buchanan AV, Weiss KM, Fullerton SM. Dissecting complex disease: the quest for the Philosopher's Stone? Int J Epidemiol 2006; 35: 562-71.

[22] Manninen P, Rihimak H, Heliovaara M. Incidence and risk factors of low back pain in middle-aged farmers. Occup Med 1995; 45: 141-6.

[23] Leboeuf-Yde C, Yashin A, Lauritzen T. Does smoking cause low back pain? Results from a population-based study. J Manipulative Physiol Ther 1996; 19: 99-108.

[24] Law MR, Hackshaw AK. A meta-analysis of cigarette smoking, bone mineral density and risk of hip fracture: recognition of a major effect. BMJ 1997; 315(7112): 841-6.

[25] Wong PK, Christie JJ, Wark JD. The effects of smoking on bone health. Clin Sci (Lond) 2007; 113: 233-41.

[26] O’Loughlin J, Lambert M, Karp I, et al. Association between cigarette smoking and C-reactive protein in a representative, 
population based sample of adolescents. Nicotine Tob Res 2008; 10: 525-32.

[27] Yanbaeva DG, Dentener MA, Creutzberg EC, Wesseling G, Wouters EF. Systemic effects of smoking. Chest 2007; 131(5): 1557-66.

[28] Kelsy JL, Githens PB, O’Conner T, et al. Acute prolapsed lumbar intervertebral disc. An epidemiologic study with special reference to driving automobiles and cigarette smoking. Spine 1984; 9(6): 608-13.

[29] Andersson HI, Ejlertsson G, Leden I. Widespread musculoskeletal chronic pain associated with smoking. An epidemiological study in a general rural population. Scand J Rehabil Med 1998; 30: 185-91.

[30] Leboeuf-Yde C, Kyvik KO, Bruun NH. Low back pain and lifestyle. Part 1: Smoking, information from a population-based sample of 29, 424 twins. Spine 1998; 23: 2207-14.

[31] Lindal E, Stefánsson JG. Connection between smoking and back pain - findings from an lcelandic general population study. Scand J Rehabil Med 1996; 28: 33-8.
[32] An HS, Silveri CP, Simpson JM, et al. Comparison of smoking habits between patients with surgically confirmed herniated lumbar and cervical disc disease and controls. J Spinal Disord 1994; 7(5): 369-73.

[33] Fogelhom RR, Alho AV. Smoking and intervertebral disc degeneration. Med Hypotheses 2001; 56(4): 537-9.

[34] Glassman SD, Dimar JR, Burkus K, et al. The efficacy of rhBMP-2 for postero lateral lumbar fusion in smokers. Spine 2007; 32(15): 1693-8.

[35] Pfirmann CW, Metzdorf A, Zanetti M, Hodler J, Boos N. Magnetic resonance classification of lumbar intervertebral disc degeneration. Spine 2001; 26: 1873-8.

[36] Griffith JF, Wang YX, Antonio GE, et al. Modified Pfirrmann grading system for lumbar intervertebral disc degeneration. Spine 2007; 32: 708-12.

Received: May 07, 2013

Revised: August 25, 2013

Accepted: August 26, 2013

(c) Sharma and Petrukhina; Licensee Bentham Open.

This is an open access article licensed under the terms of the Creative Commons Attribution Non-Commercial License (http://creativecommons.org/licenses/by-nc/3.0/) which permits unrestricted, non-commercial use, distribution and reproduction in any medium, provided the work is properly cited. 